IGUSABDER, 13 (2021): 16-29

\title{
Çocuklarda Demir Eksikliği ve Demir Eksikliği Anemisi: Tek Merkez Deneyimi
}

\author{
Gökce CELEP* ${ }^{*}$ Zeynep Hülya DURMAZ**
}

\section{$\ddot{\mathbf{O} z}$}

Amaç: Demir eksikliği (DE) ve demir eksikliği anemisi (DEA) ülkemizde ve dünyada sık görülen bir halk sağlı̆̆g sorunudur. Özellikle pediatrik yaş grubu için önemli bir tehdittir. Bu çalışmanın amacı hastanemize başvuran akut enfeksiyonu veya kronik hastalığı olmayan çocuklarda DE ve DEA sıklığını saptamaktır. Böylece destek tedavisi için yeni hedef yaş gruplarının saptanmasına katkıda bulunmak istenmektedir.

Yöntem: Araştırmaya 1 Ocak 2018-31 Aralık 2018 tarihleri arasında bir ikinci basamak sağllk kuruluşunun pediatri birimlerine başvuran çocuklar katıldı. Akut enfeksiyon bulgusu, lökositozu ve/veya C-reaktif protein yüksekliği, kronik hastalı̆̆ı, obezite veya büyüme geriliği olanlar çalışma dışı bırakıldı. Veriler hastane kayıt ve dosya sisteminden geriye dönük olarak elde edildi. Katılımcılara ait yaş, cinsiyet, sağlık durumu bilgileri, tam kan sayımı, demir, demir bağlama kapasitesi, ferritin düzeyleri kayıt altına alındı, transferrin satürasyonu hesaplandı. Elde edilen veriler istatistik paket programı ile değerlendirildi.

Bulgular: Çalışmaya yaşları 1-17 arasında değişen 125’i kız (\%58,7), 88’i erkek (\%41,3) toplam 213 çocuk katıldı. Değerlendirmeler sonunda çalışma grubunda etiyolojiden bağımsız olarak anemi sıklı̆̆ı \%29,6 bulundu. DE sıklı̆̆ı ise \%26,2 idi, bu durumun ergen yaş grubunda ve kızlarda daha sık olduğu görüldü. DEA sıklı̆̆g ise \%13, 1 idi.

Sonuç: DE ve DEA, sağlıklı görünen çocuklardan oluşan çalışma grubumuz için sık görülen bir sorundur. Demir gereksinimi diyetle karşılanamıorsa tüm çocuklara destek tedavisi

\footnotetext{
Özgün Araştırma Makalesi (Original Research Article)

Geliş / Received: 23.05.2020 \& Kabul / Accepted: 31.03.2021

DOI: https://doi.org/10.38079/iqusabder.741716

* Dr. Öğr. Üyesi, Amasya Üniversitesi, Tıp Fakültesi, Çocuk Sağlığı ve Hastalıkları Anabilim Dalı, Amasya, Türkiye, E-posta: gokce4celep@yahoo.com ORCID https://orcid.org/oooo-00016250-5096

** Uzm. Dr., Amasya Üniversitesi, Tıp Fakültesi, Biyokimya Bölümü, Amasya, Türkiye, E-posta: aakdenizhulyaa2141@gmail.com ORCID https://orcid.org/0000-0002-3260-0030
} 
uygulanmalıdır. Özgün bulguları olmayan; ama multisistemik etkileri olan DE ve DEA'nin önlenmesi bu yolla mümkündür. Sağlık kurumuna tüm başvurular ve yapılan tüm muayeneler ile tetkikler çocuk sağlı̆̆ı izlemleri için de bir firsat olarak değerlendirilmelidir.

Anahtar Sözcükler: Anemi, demir eksikliği, çocuk.

\title{
Iron Deficiency and Iron Deficiency Anemia in Children: Single-Center Experience
}

\begin{abstract}
Aim: Iron deficiency (ID) and iron deficiency anemia (IDA) are common public health problems in our country and throughout the world. They are big threats for the pediatric age group. The aim of this study is to determine the frequency of ID and IDA in children without acute infection or chronic disease who admitted to our hospital. Thus, it is desired to contribute to the identification of new target age groups for prophylactic supplementation therapy.
\end{abstract}

Methods: Children who applied to the pediatric units of a secondary health care institution between January 1, 2018 and December 31, 2018 participated in the study. Participants with acute signs of infection, leukocytosis and/or high C-reactive protein levels or chronic disease, growth retardation, obesity were excluded from the study. The data of the study were obtained from the hospital record system retrospectively. The information about age, gender, health status, complete blood count, serum iron, iron-binding capacity, ferritin levels were noted and transferrin saturations were calculated. The data were evaluated by statistical software.

Results: A total of 213 children, 125 girls (58,7\%) and 88 boys (41,3\%), aged between 1-17, participated in the study. The frequency of anemia, ignoring the etiologic reason, was found to be $29,6 \%$ in the study group. ID was detected in $26,2 \%$ of the participants and it was more frequent in adolescent girls. IDA frequency was $13,1 \%$.

Conclusion: ID and IDA are common problems for our study group, which consisted of healthylooking children. Prophylactic iron supplementation should be applied to all children if the requirement cannot be provided by the diet. In this way, it is possible to prevent ID and IDA that have no specific signs but have multistemic effects. All applications to the health institution and all examinations should also be considered as an opportunity for child health monitoring.

Keywords: Anemia, iron deficiency, child.

\section{Giriş}

Anemi "kırmızı kan hücreleri (KKH) kütlesinin ve/veya kan hemoglobin (HGB) konsantrasyonun yaş, rrk ve cinsiyete göre 2,5 persentilin altında olması” olarak 
tanımlanır'. KKH üretiminde azalma, HGB sentez bozuklukları, akut veya kronik kan kayıpları, KKH'nin herhangi bir nedenle yıkılması (immün hemolitik olaylar, hipersplenizm, vb.) gibi olaylar anemi ile sonuçlanır. Nedeni ne olursa olsun aneminin varlığı kanın oksijen $\left(\mathrm{O}_{2}\right)$ taşıma kapasitesinin azalmasına sebep olur. Vücuttaki pek çok biyokimyasal tepkimeler, hücresel işlevler, zihinsel ve akademik işlevler, fiziksel kapasite, ısı düzenlenmesi, gastrointestinal ve kardiyovasküler sistem etkinliği, büyümegelişme, bağışıklık sistemi anemi varlığında zarar görür. Anemi olumsuz multisistemik sonuçları olan klinik bir sendromdur, taranması ve nedeninin bulunup tedavi edilmesi şarttır. Aksi durumda özellikle büyüme ve gelişmenin devam ettiği çocukluk çağında tüm yaşamı olumsuz etkileyebilecek kalıcı sorunlar ortaya çıkabilir²,3. Aneminin çocuklardaki en sık nedeni besinsel eksikliklerdir; demir eksikliği de başı çekmektedir ${ }^{4}$. Bunun yanı sıra folat, B12, çinko, bakır, A vitamini gibi besinsel eksiklikler, kurşun maruziyeti, kronik hastalıklar, kronik enfeksiyonlar (sıtma, tüberküloz, bruselloz, vb.), ilaçlar, bazı akut viral enfeksiyonlar (Parvovirus B19, vb.), HGB sentezini bozan hemoglobinopatiler (talasemi sendromları, orak hücreli anemi, vb.), eritrosit membran ve enzim bozuklukları (herediter sferositoz, glukoz 6 fostat dehidrogenaz, vb.), kemik iliği yetersizliği, maligniteler, retiküloendotelyal sistem hastalıkları aneminin diğer nedenleri arasındadır5,6. Anemi evrensel bir halk sağlığı sorunudur, ancak çocuklar neden ve sonuçları açısından daha büyük risk altındadır. Dünya Sağlık Örgütü (DSÖ) verilerine göre dünya genelindeki çocuk nüfusunun yarısı anemi ve anemi ilişkili hastalıkların etkisi altındadır7. Bu kapsamda ülkemiz “orta riskli ülkeler” grubunda yer almaktadır4.

Demir eksikliği (DE) fizyolojik işlevleri gerçekleştirmek için gereken vücut demirinin yetersiz olmasıdır. DSÖ kaynaklarına göre 5 yaş altı çocuklarda ferritin düzeyinin $<12$ $\mathrm{mcg} / \mathrm{L}, 5$ yaş üstü çocuklarda $<15 \mathrm{mcg} / \mathrm{L}$ olması "demir eksikliği olarak tanımlanır8,9. Ferritin bir akut faz reaktanı olduğundan düşük olması her zaman DE’ni düşündürür. Ancak normal ya da yüksek olması bunu dışlamaz. Ferritin inflamasyon, enfeksiyon, malignite, karaciğer hastalıkları gibi olaylarda da yükselebileceğinden yüksekliği durumunda başka bir akut faz reaktanı da dikkate alınarak değerlendirilmelidir ${ }^{9,10}$. Bunun yanında transferrin satürasyonunun <\%16 olması da destekleyici bir bulgudur, ancak serum demir düzeyinin gün içinde değişiklikler göstermesi söz konusudur 9 .

DE tüm dünyada yaygındır, özellikle Asya ve Afrika için tehdit edici bir halk sağlı̆̆ sorunudur. Çocuklardaki en sık nedenleri demirden fakir beslenme veya gıda alımı 
uyumsuzlukları, emilim bozuklukları, bir yaştan önce inek sütü ile beslenme, bağırsaklardan gizli kan kaybına neden olan süt protein alerjisi, parazitoz gibi durumlar, obezite, maternal eksiklik ve prematüritedir ${ }^{11}$. Klinik olarak bir kan sayımında tesadüfen fark edilebileceği gibi, halsizlik, yorgunluk, akademik performansta düşüklük, çarpıntı, kalp yetmezliği, katılma nöbeti, pika gibi pek çok farklı tablo ile karşımıza gelebilir ${ }^{10}$. Bu bulguların ortaya çıkması için DE’nin anemiyle sonuçlanması gerekmez. Tam kan sayımında kırmızı kan hücrelerinin dağılım genişliğinin (RDW) arttığı hipokrom mikrositer anemi ise genellikle demir eksikliği anemisini (DEA) işaret eder9,10.

DEA en sık görülen ve önlenebilir anemi türüdür. Miadında doğan tüm bebeklere 4 . aydan itibaren $1 \mathrm{mg} / \mathrm{kg} /$ gün (maksimum $15 \mathrm{mg} /$ gün), preterm bebeklere 2. aydan itibaren 2-4 mg/kg/gün (maksimum $15 \mathrm{mg} /$ gün), 1-3 yaşta $7 \mathrm{mg} /$ gün, 4-8 yaşta 10 mg/gün, 9-13 yaşta 8 mg/gün, 14-18 yaşta kızlar için 15 mg/gün, erkekler için 11 mg/gün demir önerilir ${ }^{10}$. Ülkemizde 2004 yılından beri uygulanan "Demir Gibi Türkiye Projesi” kapsamında yaşamın ilk bir yılında doğum zamanı göz önüne alınarak tüm bebeklere demir desteği verilmektedir. Bu program sayesinde DEA sıklığı geçmiş yıllara göre azalmıştır $^{12}$. Benzer bir programın diğer riskli gruplar için uygulanması konusunda çalışmalar devam etmektedir. Bu çalışmanın amacı ilimizdeki referans sağlık kurumu olan hastanemize başvuran çocuklarda DE ve DEA sıklığını saptamak ve ülkemizin yeni destek programları için hedef yaş gruplarının belirlenmesine katkı sağlamaktır.

\section{Gereç ve Yöntem}

Bu araştırmada, Orta Karadeniz'de 411 m. rakımlı küçük bir il merkezindeki referans hastanenin çocuk polikliniklerine 1 Ocak 2018-31 Aralık 2018 tarihleri arasında ayaktan başvuran, yaşları 1-17 arasında değişen çocuklar değerlendirilmiştir. Hastalara ait bilgiler hastanenin kayıt sisteminden geriye dönük olarak incelenmiştir. Bilinen kronik hastalığı olanlar, yaş ve cinsiyet göz önüne alınarak değerlendirildiğinde vücut ağırlığı ve boy ölçümleri 3-97. persentil dışında olanlar, Vücut Kitle İndeksi \%95’in üzerinde olanlar, muayeneleri sonucunda kronik hastalık tanısı alanlar, akut enfeksiyon saptananlar, lökositozu ve/veya C-reaktif protein (CRP) yüksekliği olanlar veya hastaneye yatış yapılanlar, herhangi bir nedenle sürekli ilaç kullananlar, son 3 ay içinde anemi tedavisi veya kan ürünü alanlar çalışma dışı bırakılmıştır. Ferritin düzeyi >30 mcg/L ve/veya lökositozu, CRP yüksekliği olan katılımcılar da değerlendirilmeye alınmamıştır. Katılımcılara ait yaş, cinsiyet, tam kan sayımı (TKS), demir, demir 
bağlama kapasitesi (DBK), ferritin düzeyleri hastane kayıtlarından elde edilmiş, transferrin satürasyonu [Demir/DBK×100] formülü ile hesaplanmıştır. Katılımcılar belirtilen şekilde yaş gruplarına ayrılmıştır: 1 . grup: 1 yaş, 2. grup: 2-3 yaş, 3. grup: 4-6 yaş, 4. grup: 7-10 yaş, 5. grup: 11-14 yaş, 6. grup: 15-17. Yaş gruplarına göre hemoglobin (HGB), ortalama eritrosit hacmi (MCV), eritrosit dağılım genişliği (RDW) persentil değerleri referans aralıklarına göre düzenlenmiştir ${ }^{13}$ (Tablo1). Ferritin 5 yaş altı çocuklarda $<12 \mathrm{mcg} / \mathrm{L}, 5$ yaş üstü çocuklarda $<15 \mathrm{mcg} / \mathrm{L}$ olduğunda, transferrin satürasyonu <\%16 olduğunda "düşük" olarak değerlendirildi9.

Tablo 1. Yaşa ve cinse göre normal TKS değerleri'13

\begin{tabular}{|c|c|c|c|c|c|c|c|c|c|c|}
\hline \multicolumn{11}{|c|}{ Hematokrit (HCT) (\%) } \\
\hline & \multicolumn{2}{|c|}{$2,5 \mathrm{p}$} & \multicolumn{2}{|c|}{$50 \mathrm{p}}$. & \multicolumn{2}{|c|}{$90 \mathrm{p}}$. & \multicolumn{2}{|c|}{$97,5 \mathrm{p}$. } & \multicolumn{2}{|c|}{ Medyan } \\
\hline Yaş & $\mathrm{E}$ & K & $\mathrm{E}$ & $\mathrm{K}$ & $\mathrm{E}$ & $\mathrm{K}$ & $\mathrm{E}$ & K & & \\
\hline 1 & \multicolumn{2}{|c|}{32,0} & \multicolumn{2}{|c|}{37,0} & \multicolumn{2}{|c|}{40,0} & \multicolumn{2}{|c|}{41,0} & \multicolumn{2}{|c|}{$35,3(3,3)$} \\
\hline $2-3$ & \multicolumn{2}{|c|}{33,0} & \multicolumn{2}{|c|}{37,0} & \multicolumn{2}{|c|}{40,5} & \multicolumn{2}{|c|}{41,0} & \multicolumn{2}{|c|}{$35,6(3,9)$} \\
\hline $4-6$ & \multicolumn{2}{|c|}{34,0} & \multicolumn{2}{|c|}{38,0} & \multicolumn{2}{|c|}{42,0} & \multicolumn{2}{|c|}{42,5} & \multicolumn{2}{|c|}{$36,8(4,0)$} \\
\hline $7-10$ & \multicolumn{2}{|c|}{35,0} & \multicolumn{2}{|c|}{39,5} & \multicolumn{2}{|c|}{43,5} & \multicolumn{2}{|c|}{45,0} & \multicolumn{2}{|c|}{$39,0(3,4)$} \\
\hline $11-14$ & \multicolumn{2}{|c|}{36,5} & 42,0 & 40,0 & 47,5 & 44,0 & 48,0 & 45,0 & $40,5(4,3)$ & $40,0(3,6)$ \\
\hline $15^{-18}$ & 40,0 & 34,0 & 46,0 & 40,0 & 50,0 & 43,5 & 51,5 & 44,5 & $44,6(4,7)$ & $39,9(4,8)$ \\
\hline \multicolumn{11}{|c|}{ Hemoglobin (HGB) (g/dl) } \\
\hline Yaş & \multicolumn{2}{|c|}{$2,5 \mathrm{p}$} & \multicolumn{2}{|c|}{$50 \mathrm{p}}$. & \multicolumn{2}{|c|}{$90 \mathrm{p}}$. & \multicolumn{2}{|c|}{$97,5 \mathrm{p}}$. & \multicolumn{2}{|c|}{ Ort \pm SS } \\
\hline & $\mathrm{E}$ & $\mathrm{K}$ & $\overline{\mathrm{E}}$ & $\mathrm{K}$ & $\bar{E}$ & $\mathrm{~K}$ & $\mathrm{E}$ & $\mathrm{K}$ & & \\
\hline 1 & & & 12 & & & & & & & $\pm 1,5$ \\
\hline $2-3$ & & & 12 & & & & & & & $=1,1$ \\
\hline $4-6$ & & & 12 & & & & & & & $=1,3$ \\
\hline $7-10$ & & & & & & & & & & $=1,0$ \\
\hline $11-14$ & 12,6 & 12,3 & 14,3 & 13,7 & 16,0 & 14,9 & 16,1 & 15 & $13,4 \pm 0,6$ & $12,7 \pm 1,9$ \\
\hline $15^{-18}$ & 13,7 & 11,5 & 15,4 & 13,7 & 17,0 & 14,9 & 17,2 & 15 & $15,3 \pm 1,0$ & $12,4 \pm 1,0$ \\
\hline & & & rmıl & kan 1 & cresi & sayıs & (KKH & $\left(10^{6}\right)$ & $\left.\mathbf{m}^{3}\right)$ & \\
\hline Yaş & & & & & & & & $\mathrm{p}$. & & SS \\
\hline & $\mathrm{E}$ & K & $\mathrm{E}$ & $\mathrm{K}$ & $\mathrm{E}$ & $\mathrm{K}$ & $\mathrm{E}$ & K & & \\
\hline 1 & & & 4 , & & & & & & 4,6 & ,56) \\
\hline
\end{tabular}




\begin{tabular}{|c|c|c|c|c|c|c|c|c|c|c|}
\hline $2-3$ & \multicolumn{2}{|c|}{4,00} & \multicolumn{2}{|c|}{4,50} & \multicolumn{2}{|c|}{5,05} & \multicolumn{2}{|c|}{5,10} & \multicolumn{2}{|c|}{$4,62(0,53)$} \\
\hline $4-6$ & \multicolumn{2}{|c|}{4,00} & \multicolumn{2}{|c|}{4,50} & \multicolumn{2}{|c|}{5,05} & \multicolumn{2}{|c|}{5,20} & \multicolumn{2}{|c|}{$4,69(0,53)$} \\
\hline $7-10$ & \multicolumn{2}{|c|}{4,05} & \multicolumn{2}{|c|}{4,60} & \multicolumn{2}{|c|}{5,20} & \multicolumn{2}{|c|}{5,30} & \multicolumn{2}{|c|}{$4,82(0,52)$} \\
\hline 11-14 & 4,3 & 4,00 & 4,85 & 4,60 & 5,50 & 5,10 & 5,60 & 5,25 & $4,91(0,63)$ & $4,77(0,49)$ \\
\hline $15-18$ & $4,4 !$ & 3,80 & 5,15 & 4,50 & 5,65 & 4,95 & 5,75 & 5,05 & $5,13(0,58)$ & $4,64(0,49)$ \\
\hline \multicolumn{11}{|c|}{ Ortalama Eritrosit Hacmi (Mean Cell Volume) (MCV)(fL) } \\
\hline Yaş & \multicolumn{2}{|c|}{$2,5 \mathrm{p}$} & \multicolumn{2}{|c|}{$50 \mathrm{p}}$. & \multicolumn{2}{|c|}{$90 \mathrm{p}}$. & \multicolumn{2}{|c|}{$97,5 \mathrm{p}}$. & \multicolumn{2}{|c|}{ Ort \pm SS } \\
\hline & $\mathrm{E}$ & K & $\mathrm{E}$ & K & $\mathrm{E}$ & $\mathrm{K}$ & $\mathrm{E}$ & K & & \\
\hline 1 & \multicolumn{2}{|c|}{71,0} & \multicolumn{2}{|c|}{79,5} & \multicolumn{2}{|c|}{84,0} & \multicolumn{2}{|c|}{85,5} & \multicolumn{2}{|c|}{$76,0(7,9)$} \\
\hline $2-3$ & \multicolumn{2}{|c|}{74,0} & \multicolumn{2}{|c|}{81,5} & & & & & 77 , & $6,5)$ \\
\hline $4-6$ & & & 8 & & 90 & & & & 79 , & $5,3)$ \\
\hline 7-10 & & & 8 & & 90 & & & & 81 , & $5,1)$ \\
\hline $11-14$ & & & 87 & & 9 & & & & 83, & $6,8)$ \\
\hline $15-18$ & & & $8 c$ & & 9 & & & & 86 , & $7,0)$ \\
\hline & alam & $\overline{\text { Eritr }}$ & sit He & $\begin{array}{l}\text { noglc } \\
\text { once }\end{array}$ & $\begin{array}{l}\text { bin Kc } \\
\text { tratio }\end{array}$ & $\begin{array}{l}\text { nsant } \\
\text { ) }(M\end{array}$ & $\begin{array}{l}\text { asyo } \\
\text { HC) }\end{array}$ & $\begin{array}{l}\text { u (Me } \\
\text { s/dl) }\end{array}$ & n Cell Hen & globin \\
\hline Yaş & & & 50 & & 90 & & & 5 . & & ESS \\
\hline & $\mathrm{E}$ & $\mathrm{K}$ & $\mathrm{E}$ & $\mathrm{K}$ & $\mathrm{E}$ & $\mathrm{K}$ & $\mathrm{E}$ & $\mathrm{K}$ & & \\
\hline 1 & & & & & & & & & 32 , & $(1,5)$ \\
\hline $2-3$ & & & 3 & & 3 & & & & 32 , & $(1,5)$ \\
\hline $4-6$ & & & 3 & & 3 & & & & 32 , & $(1,5)$ \\
\hline $7-10$ & & & 3 & & 3 & & & & 32 , & $(1,3)$ \\
\hline $11-14$ & & & 3 & & 3 & & & & 32 , & $(1,5)$ \\
\hline $15-18$ & & & $3:$ & & & & & & 32 , & $1,4)$ \\
\hline & tala & a Erit & osit H & mog & obini & Mean & Cell I & $\overline{\operatorname{emog}}$ & bini) (MC) & (pg) \\
\hline Yaş & 2,5 & & $50 \mathrm{p}$. & & $90 \mathrm{p}$. & & 97,5 & & & $\mathrm{ESS}$ \\
\hline & $\mathrm{E}$ & $\mathrm{K}$ & $\mathrm{E}$ & $\mathrm{K}$ & $\mathrm{E}$ & $\mathrm{K}$ & $\mathrm{E}$ & $\mathrm{K}$ & & \\
\hline 1 & & & & & & & & & 24, & $3,1)$ \\
\hline $2-3$ & & & & & 30 & & & & 25 & $2,3)$ \\
\hline $4-6$ & & & & & 30 & & & & 26 , & $1,9)$ \\
\hline $7-10$ & & & $2 C$ & & & & & & 26 , & $2,1)$ \\
\hline 11-14 & & & 24 & & & & & & 27 & $2,7)$ \\
\hline
\end{tabular}




\begin{tabular}{|c|c|c|c|c|c|c|c|c|c|c|}
\hline $15-18$ & \multicolumn{2}{|c|}{27,0} & \multicolumn{2}{|c|}{30,2} & \multicolumn{2}{|c|}{32,5} & \multicolumn{2}{|c|}{32,8} & \multicolumn{2}{|c|}{$28,3(2,8)$} \\
\hline \multicolumn{11}{|c|}{ Eritrosit Dağılım Genişliği (Red Cell Distribution Width) (RDW) (109/1) } \\
\hline Yaş & \multicolumn{2}{|c|}{$2,5 \mathrm{p}$. } & \multicolumn{2}{|c|}{$50 \mathrm{p}$} & \multicolumn{2}{|c|}{$90 \mathrm{p}$. } & \multicolumn{2}{|c|}{$97,5 \mathrm{p}}$. & \multicolumn{2}{|c|}{ Ort \pm SS } \\
\hline & $\mathrm{E}$ & K & $\mathrm{E}$ & K & $\mathrm{E}$ & $\mathrm{K}$ & $\mathrm{E}$ & $\mathrm{K}$ & & \\
\hline 1 & \multicolumn{2}{|c|}{11,8} & \multicolumn{2}{|c|}{13,1} & \multicolumn{2}{|c|}{15,5} & \multicolumn{2}{|c|}{17,0} & \multicolumn{2}{|c|}{$14,7(2,3)$} \\
\hline $2-3$ & \multicolumn{2}{|c|}{11,4} & \multicolumn{2}{|c|}{12,4} & \multicolumn{2}{|c|}{14,1} & \multicolumn{2}{|c|}{14,6} & \multicolumn{2}{|c|}{$13,9(1,6)$} \\
\hline $4-6$ & \multicolumn{2}{|c|}{11,4} & \multicolumn{2}{|c|}{12,2} & \multicolumn{2}{|c|}{13,2} & \multicolumn{2}{|c|}{13,5} & \multicolumn{2}{|c|}{$13,7(1,4)$} \\
\hline $7-10$ & \multicolumn{2}{|c|}{11,4} & \multicolumn{2}{|c|}{12,2} & \multicolumn{2}{|c|}{13,2} & \multicolumn{2}{|c|}{13,4} & \multicolumn{2}{|c|}{$13,4(1,1)$} \\
\hline $11-14$ & \multicolumn{2}{|c|}{11,3} & \multicolumn{2}{|c|}{12,2} & \multicolumn{2}{|c|}{13,4} & \multicolumn{2}{|c|}{13,6} & \multicolumn{2}{|c|}{$13,5(1,1)$} \\
\hline $15-18$ & \multicolumn{2}{|c|}{11,4} & \multicolumn{2}{|c|}{12,2} & 13,2 & 13,8 & 13,6 & 14,4 & $13,2(1,0)$ & $13,6(1,7)$ \\
\hline
\end{tabular}

p.: persentil

Tam kan sayımı (TKS), demir, DBK, ferritin ölçümleri venöz kan örneklerinden çalışıldı. TKS lazer optik sistem prensibiyle çalışan Mindray BC-680o® (Shenzhen Mindray BioMedical Electronics Co. Ltd, Çin),otomatik analiz cihazı ile çalışıldı. Ferritin düzeyleri Siemens Advia Centaur XP®, (Siemens, Erlangen, Almanya) cihazında kemiluminesans yöntemiyle analiz edildi. Demir 2,4,6 Tri (2-pridil) 5-tiazin ile kromojen oluşturduğu “colour" tekniği ile demir bağlama kapasitesi Nitroso-PSAPS'nin kullanıldığı "colour" yöntemiyle Beckman Coulter AU 5800® (Brea California, ABD) cihazıyla çalışıldı.

Çalışma için Amasya Üniversitesi Girişimsel Olmayan Klinik Araştırmalar Etik Kurulu’ ndan 27.02.2020-E.5675 evrak tarih ve sayısı ile onay belgesi alındı.

\section{İstatistiksel Analiz}

Katılımcılara ait veriler SPSS paket programıla analiz edildi (SPSS version 15 (SPSS, Inc., Chicago, IL, USA). Tanımlayıcı analizlerle sıklık, ortalama, ortanca, en düşük- en yüksek değerler, çeyrekler arası uzaklık, standart sapma bulundu. Verilerin normal dağılıma uyup uymadığı görsel (histogram) ve analitik (Kolmogorov-Simirnov) uygunluk testleriyle değerlendirildi. İkili gruplar çapraz tablolar ki-kare testi, Fisher exact test ve Pearson testi ile karşılaştırıldı. p<0,05 değeri istatistiksel olarak anlamlı kabul edildi.

\section{Bulgular}

Çalışmaya yaşları 1-17 arasında değişen (ortanca: 6 yıl) 88’i erkek (\%41,3), 125’i kız $(\% 58,7)$ olmak üzere toplam 213 sağlıklı çocuk katıldı. 
Birinci gruptaki 24 çocuğun \%54,2'si (n=13) erkek, \%45,8’i (n=11) kız idi. Tüm grubun

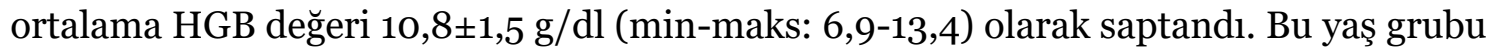
için belirlenen alt sınır 10,5 g/dl idi, katılımcıların \%25’inde (n=6) anemi mevcuttu. Anemik olguların beşinde (\%83,3) mikrositoz vardı, RDW ise 3 olguda artmıştı. Aynı grupta 10 olguda ferritin değeri düşük bulundu $(\% 41,7)$.

İkinci grupta 22'si erkek $(\% 52,4)$, 20'si $(\% 47,6)$ klz olmak üzere toplam 42 hasta mevcuttu. Olguların \%23,8'inde $(\mathrm{n}=10)$ anemi saptandı, RDW artmış mikrositik anemi oranı ise \%14,3 $(\mathrm{n}=6)$ bulundu. Grupta DE oranı \%26,2 $(\mathrm{n}=11)$, transferrin satürasyonu düşüklüğü sıklığı ise \%54,8 (n=23) idi. Anemik olguların beşinde (\%50) hem ferritin, hem transferrin satürasyonu düşüktü.

Üçüncü grup üyelerinin \%44,7’si (n=21) erkek, \%55,3’ü (n=26) kızdı. Toplam 47 hastanın

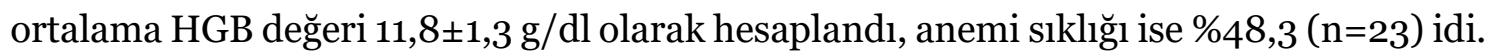
Mikrositoz tüm grupta $13(\% 27,7)$ hastada saptandı ve bunların 10 tanesinde $(\% 71,4)$ RDW'nin arttığı anemi mevcuttu. Yine anemik olguların yedisinde $(\% 30,4)$ ferritin, 13 ’̈̈nde $(\% 56,5)$ transferrin satürasyonu düşük bulundu.

Dördüncü grup toplam 30 katılımcıdan oluşuyordu ve bunların 12'si (\%40) erkek, 18’i

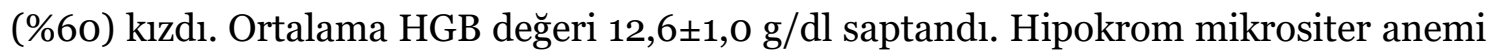
5 anemik hastanın üçünde mevcuttu ve bunların hepsinde RDW artmıştı. Altı (\%20) hastada ferritin düşük bulundu, bunların ikisi anemikti.

Beşinci grupta dokuzu erkek (\%33,3), 18’i kız $(\% 66,7) 27$ katılımcı vardı. Kızlar için HGB alt sınır değeri 12,3 g/dl, erkekler için 12,6 g/dl olarak tanımlanmıştı. Buna göre kızlarda anemi sıklığı \%27,7 (n=5), erkeklerde ise \%11,1 $(n=1)$ idi. Bir erkek katılımcıda DE olmasına rağmen anemi saptanmadı. İki anemik kız katılımcıda ferritin düzeyi düşük bulundu, bir hastada izole DE mevcuttu. Anemisi olan beş kız katılımcının dördünde ise transferrin satürasyonu düşüktü.

Altıncı grup, 10’u (\% 23,8) erkek, 32'si $(\% 76,2)$ kız olmak üzere toplam 42 katılımcıdan oluşuyordu. Erkekler arasında sadece bir katılımcıda anemi saptandı, hiçbir katılımcıda ferritin düşüklüğü saptanmadı; ancak dört olguda transferrin satürasyon düşüktü;

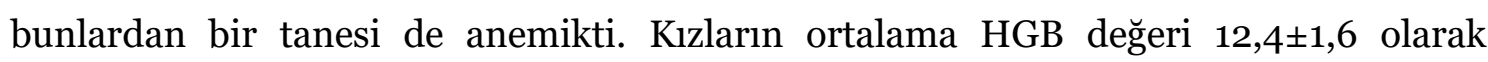
hesaplandı. Dokuz hastada anemi bulundu, bunların yedisinde $(\% 87,5)$ RDW artışı ve hipokrom mikrositer anemi vardı. Bu anemik olguların altısında transferrin satürasyonu 
düşük bulundu. Anemi olmaksızın ferritin düşüklüğü yedi kız katılımcıda mevcuttu $(\% 30,4)$.

Tüm çalışma grubu göz önüne alındığında anemi oranı \%29,6 (n=63) idi. Erkeklerin \%27,2'sinde ( $n=24)$, kızların \%31,2'sinde $(n=39)$ anemi mevcuttu. Genel olarak bakıldığında cinsiyetler arasında anemi sıklığı açısından istatiksel fark yoktur. Ancak yaş grupları dikkate alındığında altıncı grupta kız çocuklarında daha yüksek saptanan oran istatistiksel olarak anlamlıydı ( $<<0,001)$ (Tablo 2). Ferritin düşüklüğü erkeklerin \%23,8'inde ( $n=21)$; kızların \%28'inde $(n=35)$ mevcuttu. Tüm gruptaki oran ise \%26,2 $(n=56)$ idi. DE sıklığı açısından yaş grupları içinde altıncı grup dışında yine fark yoktur, bu grupta DE sıklığı kız çocuklarında anlamlı olarak daha yüksekti ( $p=0,028)$. DE ile birlikte anemi varlığı; yani DEA sıklı̆̆ı ise ferritin düzeyi dikkate alındı̆̆ında kız çocuklarında 19 hastada (tüm kız çocuk nüfusu içinde \%15,2; anemik kız çocukları içinde \%48,7), erkek çocuklarında dokuz hastada (tüm erkek çocukları nüfusu içinde \%10,2; anemik erkek çocukları içinde \%37,5) saptandı. Tek başına DE erkeklerin 10 tanesinde (\%11,3); kızların 13 tanesinde mevcuttu $(\% 10,4)$, bu açıdan cinsiyetler arasında anlamlı fark saptanmadı. Erkeklerin \%15,9'unda $(n=14)$, kızların \%21,6'sında (n=27) transferrin satürasyon düşüklüğü ile birlikte anemi mevcuttu. Sadece transferrin satürasyon düşüklüğü oranı ise kızlarda \%20,8 $(n=26)$, erkeklerde ise \%25 $(n=22)$ idi. Anemik grupta kızların baskınlığı, anemik olmayan grupta ise erkeklerin baskınlığı istatistiksel olarak anlamlıydı ( $\mathrm{p}=0,035 ; \mathrm{p}=0,04 ;$ sirasıyla). Ağır anemi $(\mathrm{HGB}<7 \mathrm{~g} / \mathrm{dl})$ sadece bir olguda saptandı (HGB:6,8 g/dl).

Tablo 2. Katılımcıların özellikleri ve anemiyle ilgili değişkenler çalışma grubu içindeki dağılım özellikleri

\begin{tabular}{|c|c|c|c|c|c|c|c|}
\hline Yaş & $\begin{array}{c}\text { Cinsiyet } \\
(\mathrm{E} / \mathrm{K})\end{array}$ & $\begin{array}{c}\text { Hb } \\
(\mathrm{G} / \mathrm{Dl})\end{array}$ & $\begin{array}{c}\text { Anemi } \\
\text { Oranı } \\
\text { n(\%) }\end{array}$ & $\begin{array}{c}\text { Mikrositoz } \\
\text { n(\%) }\end{array}$ & $\begin{array}{c}\text { Artmiş } \\
\text { Rdw } \\
\text { n(\%) }\end{array}$ & $\begin{array}{c}\text { Düşük } \\
\text { Ferritin } \\
\text { n(\%) }\end{array}$ & $\begin{array}{c}\text { Düşük } \\
\text { Transferrin } \\
\text { Satürasyonu } \\
\text { n(\%) }\end{array}$ \\
\hline 1 & $13 / 11$ & $10,8 \pm 1,5$ & $6(25)$ & $6(25)$ & $4(16,6)$ & $10(41,7)$ & $10(41,7)$ \\
\hline $2-3$ & $22 / 22$ & $11,5 \pm 1,1$ & $10(23,8)$ & $7(16,7)$ & $16(38,1)$ & $11(26,2)$ & $23(54,8)$ \\
\hline $4-6$ & $21 / 26$ & $11,8 \pm 1,3$ & $23(48,3)$ & $13(27,7)$ & $26(55,3)$ & $11(23,4)$ & $21(44,7)$ \\
\hline $7-10$ & $12 / 18$ & $12,6 \pm 1,0$ & $8(26,7)$ & $5(16,7)$ & $17(56,6)$ & $6(20)$ & $13(43,3)$ \\
\hline 11-14 & $9 / 18$ & $\begin{array}{l}\text { E: } 13,4 \pm 0,6 \\
K: 12,7 \pm 1,9\end{array}$ & $\begin{array}{l}\mathrm{E}: 1(11,1) \\
\mathrm{K}: 5(27,8)\end{array}$ & $\begin{array}{l}\mathrm{E}: 3(33,3) \\
\mathrm{K}: 6(33,3)\end{array}$ & $\begin{array}{l}\text { E:5(44,4) } \\
\text { K:11(61,1) }\end{array}$ & $\begin{array}{l}\mathrm{E}: 1(11,1) \\
\mathrm{K}: 3(16,7)\end{array}$ & $\begin{array}{l}\mathrm{E}: 2(22,2) \\
\mathrm{K}: 6(33,3)\end{array}$ \\
\hline $15-17$ & $10 / 32$ & $\begin{array}{l}\text { E: } 15,3 \pm 1,0 \\
K: 12,4 \pm 1,6\end{array}$ & $\begin{array}{c}\text { E:1(10) } \\
\text { K:9(28,1) }\end{array}$ & $\begin{array}{c}\text { E: } 2(20) \\
K: 12(37,5)\end{array}$ & $\begin{array}{c}\mathrm{E}: 4(40) \\
\mathrm{K}: 12(37,5)\end{array}$ & $\begin{array}{c}\mathrm{E}: 0 \\
\mathrm{~K}: 14(43,8)\end{array}$ & $\begin{array}{c}\mathrm{E}: 4(40) \\
\mathrm{K}: 13(40,6)\end{array}$ \\
\hline
\end{tabular}




\section{Tartışma}

Demir eksikliği gelişmiş ülkeler dâhil, tüm dünyada yaygın bir beslenme sorunudur ${ }^{4,14}$. Kazanılmış anemilerin en sık nedeni olarak karşımıza çıkar. Tüm anemilerde olduğu gibi halsizlik, yorgunluk, iştahsızlık, çarpıntı, akademik performansta, efor kapasitesinde azalmaya neden olur. Nörolojik ve kognitif gelişim için çok önemli olan demir elementinin eksikliği hem çocuklukta, hem erişkinlikte yaşam kalitesini düşürür²,13. Önlenebilir bir halk sağlığı olan DE ve DEA'nin her firsatta değerlendirilmesi ve gerekli durumlarda tedavi edilmesi istenir. Bizim çalışmamızda olduğu gibi sağlıklı görünen çocuklarda da sık rastlanan bir durumdur. Erken bebeklikte fetal hemoglobinden (HBF) erişkin tip hemoglobine (HBA2) geçiş sürecinde gelişen fizyolojik anemiden sonra tükenen demir depoları, 4-6 aydan itibaren demir desteğini gerekli kılar. Ülkemizde bu gereksinimi karşlamak için erken doğan bebeklere 2. aydan itibaren $2-4 \mathrm{mg} / \mathrm{kg} / \mathrm{gün}$, miadında doğan bebeklere 4. aydan itibaren 1-2 $\mathrm{mg} / \mathrm{kg} /$ gün demir desteği önerilmektedir. Demir desteği izlemlerini aile sağlı̆̆ı merkezleri yürütmektedir. "Demir gibi Türkiye projesi” öncesinde ülkemizin değişik yörelerinden yapılan ve farklı yaş gruplarını kapsayan çalışmalarda DEA sıklığı \%15-30 civarında saptanmıştır. Özellikle bebeklerde sıklı̆̆ın \%50'ye yaklaştığını bildiren raporlar yayınlanmıştır ${ }^{15,16}$. Bu gayretlerin sonucu olarak proje sonrasında yapılan çalışmalar DEA'nin daha önceki yllara göre azaldığını; ancak hala önemli bir halk sağlığı olduğunu gösterir niteliktedir ${ }^{12,17}$. Tüm dünyayı yansıtan bir rapora göre de 32 milyon gebe kadın ve 273 milyon çocuk anemi tehdidi altındadır ${ }^{18}$. Bu çalışmada da tüm grup dikkate alındığında anemi sıklı̆̆ı \%29,6 ‘dır; ayrıca 15-17 yaş grubunda anemi ve ferritin düşüklüğü sıklı̆̆ının özellikle kızlarda artmış olması dikkat çekicidir. Hem DE, hem DEA ilimiz için önemli bir halk sağlığı sorunudur.

DE ve DEA genellikle birlikte anılan kavramlardır. Ancak DE anemiden önceki süreci tanımlayan bir durumdur, eksiklik yerine konmazsa anemiyle sonuçlanacaktır. Demir vücudumuzda pek çok işlev için önemli bir elementtir. Anemi olmadan da eksikliği fiziksel kapasitede azalma, halsizlik, akademik performansta azalma, huzursuzluk, açıklanamayan ağrı sendromları gibi sorunlara neden olabilir²,9. Sıklığının DEA'dan daha fazla olması dikkat çekicidir. DE tanısı genellikle ferritin düzeyi ölçümü ile konur. Ferritin bir akut faz reaktanı olduğundan inflamatuvar yanıtın tetiklendiği her durumda artabilir. $\mathrm{Bu}$ nedenle ferritinin $>30 \mathrm{mcg} / \mathrm{L}$ olduğu durumlar $\mathrm{DE}$ ve DEA 
değerlendirilmesinde tek başına güvenilir değildir ${ }^{9}$. Serum demirinin neredeyse tamamı transferrine bağlı olarak taşınmakta ve gün içinde farklılıklar göstermektedir. Demir eksikliği anemisinde de beklendiği üzere bu bağlanma ve transferrinin demirle doygunluğu azalır. Sabahları daha yüksek, akşamları daha düşük değerlerde olması nedeniyle kan örneklerinin sabah ya da öğleden önce alınması önerilmektedir ${ }^{19}$. Ancak bu çalışmada kan örneklerinin alınma saati dikkate alınmamıştır. Çalışmanın eksik yanlarından biri olan bu durum transferrin satürasyon düşüklüğü sıklığının ferritin düzeyi düşüklüğünden daha fazla olmasını açıllayabilir.

TKS’nın ayrıntılı değerlendirilmesi, anemi tanısında pek çok bilgiyi içermektedir. Ayrıcı tanıya yaklaşımda kesin testlerin belirlenmesi için maliyet ve zaman kazanılmasını

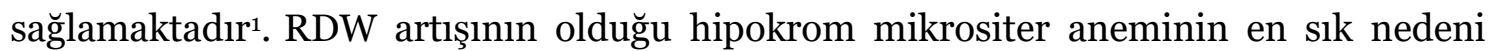
DEA'dir ${ }^{1}$. Ülkemiz talasemi sendromları için de endemik bölgedir, akraba evliliklerinin fazla olması nedeniyle taşıyıcılık oranı yüksektir. Burada bebeklikten itibaren dikkat çeken RDW'nin normal olduğu hipokrom mikrositer anemi söz konusudur ${ }^{20,21}$. Ayrıca Mentzer indeksi (MCV/KKH) 13’ün altındadır. Talasemi taşıyıcılarında da DE nadir bir durum değildir ${ }^{1}$ Kesin tanı için hemoglobin elektroforezi gereklidir ${ }^{21}$.

Hem DE, hem DEA erken çocuklukta erkeklerde daha sıkken, yaş arttıkça, özellikle ergenlik döneminde kızlarda daha fazla oranda görülür ${ }^{10,22}$. Türkiye Cumhuriyeti Sağlık Bakanlığı bebek ve çocuk izlem protokollerine göre 9. ay, 5 yaş ve ergenlik dönemlerinde anemi taraması önerilmektedir ${ }^{23}$. Büyümenin arttığı dönemlerde demir gereksinimi de artar. Ergen kızlarda menstrasyonla oluşan kayıplar, erkeklerde artan kas kütlesi demir gereksinimini arttırmaktadır ${ }^{9,24}$. Bu dönemlerde en az bir kez aneminin taranması; büyüme-gelişme geriliği, prematürite, malnütrisyon, beslenme ve emilim bozukluğu, yoğun süt tüketimi, kanama öyküsü gibi risk faktörleri varsa DE yönünden de hastaların değerlendirilmesi önerilmektedir ${ }^{10,11,24}$. Derin aneminin de en slk nedeni beslenme bozukluğuna bağlı demir eksikliği anemisidir, süt çocukluğu döneminde de ergenlikte de önemli bir sorundur ${ }^{25,26}$.

Retrospektif olarak tasarlanan ve sunulan bu çalışmanın pek çok kısıtlılıkları mevcuttur. Sadece hastane kayıtlarının değerlendirildiği, hastaların klinik özellikleri, özgeçmiş, aile, sosyoekonomik durum, yaşanılan yer, beslenme öyküleri ve takiplerinin bildirilmemesi çalışmamızın önemli eksik yanlarından bazılarıdır. Sadece hastaneye başvuran çocuklar incelendiğinden tüm nüfusu yansıtmamaktadır. 


\section{Sonuç ve Öneriler}

Tüm yönleriyle DE ve DEA ilimiz, ülkemiz ve dünyamızda sık bir halk sağlığı sorunudur. Demir eksikliğini saptamak için riskli olgularda demir düzeyleri değerlendirilmelidir; ancak olanaklar kısıtlıysa destek tedavileri, zenginleştirilmiş gıdalar, beslenme konusunda annelerin eğitimi, demir tedavisi konusunda ailelerin bilgilendirilmesinin koruyucu hekimlik açısından yararlı olacağı düşünülmektedir.

\section{KAYNAKLAR}

1. Sandoval C. Approach to the child with anemia Uptodate. http://www.uptodate.com Yayınlanma tarihi: Haziran 2019. Erişim tarihi 22 Nisan 2020.

2. Pasricha SR. Should we screen for iron deficiency anaemia? A review of the evidence and recent recommendations. Pathology. 2012;44(2):139-147. doi: 10.1097/PAT.obo13e32834e8291.

3. Stoltzfus RJ, Mullany L, Black RE. Iron deficiency anaemia. In: Ezzati M, Lopez Ad, Rodgers A, Murray CJL eds. Comparative quantification of health risks: global and regional burden of disease attributable to selected major risk factors. Geneva: World Health Organization; 2004.

(http://www.who.int/publications/cra/chapters/volume1/01630210.pdf?ua=1). Erişim tarihi 23 Nisan 2020: 163-210.

4. World Health Organization. The global prevalence of anaemia in 2011. Geneva: World Health Organization; 2015.

5. Balarajan Y, Ramakrishnan U, Ozaltin E, Shankar AH, Subramanian SV. Anaemia in low-income and middle-income countries. Lancet. 2011;378(9809):2123-35. doi:10.1016/So140-6736(10)62304-.

6. Tolentino K, Friedman JF. An update on anemia in less developed countries. Am J Trop Med Hyg. 2007;77(1):44-51.

7. McLean E, Cogswell M, Egli I, Wojdyla D, De Benoist B. Worldwide prevalence of anaemia, WHO Vitamin and Mineral Nutrition Information System, 19932005. Public Health Nutr. 2009;12(4):444-54.

8. World Health Organization. Serum ferritin concentrations for the assessment of iron status and iron deficiency in populations. Vitamin and Mineral Nutrition 
Information System. Geneva: World Health Organization; 2011. Publication No. WHO/NMH/NHD/MNM/11.2.http://www.who.int/vmnis/indicators/serum f erritin.pdf. Erişim tarihi 31 Ocak 2020.

9. Sills R. Iron defîciency anemia. In: Kliegman RM, Stanton B, St. Geme S, Schor N, eds. Nelson Textbook of Pediatrics. 2oth ed. Philadelphia: Elsevier; 2015:2323-6.

10. Powers JM, Mahoney DH. Iron deficiency in infants and children under 12 years: Screening, prevention, clinical manifestations, and diagnosis. Uptodate. http://www.uptodate.com Yayınlanma tarihi Mart 2020. Erişim tarihi 22 Nisan 2020.

11. Baker RD, Greer FR, Committee on Nutrition American Academy of Pediatrics. Diagnosis and prevention of iron deficiency and iron-deficiency anemia in infants and young children (0-3 years of age). Pediatrics. 2010;126(5):1040. doi:10.1542/peds.2010-2576.

12. Vatandaş N, Atay G, Tarcan A, Kanra S, Özbek N. Hayatın ilk yılında demir profilaksisi ve anemi. Çocuk Sağlığı ve Hastalıkları Dergisi. 2007;50:12-5.

13. Brugnara C, Oski FA, Nathan DG. Diagnostic approach to the anemic patient. In: Orkin SH, Fisher DE, Ginsburg D, et al, (Eds). Nathan and Oski's Hematology and Oncology of Infancy and Childhood. 8th ed. Philadelphia: WB Saunders; 2015.

14. Lerner NB. The anemias. In: Kliegman RM, Stanton BF, St Geme JW, Schor NF, (Eds). Nelson textbook of pediatrics. 2oth ed. Philadelphia (PA): Elsevier; 2015.

15. Kocak R, Alparslan ZN, Ağridağ G, Başlamıslı F, Aksungur PD, Koltaş S. The frequency of anaemia, iron deficiency, hemoglobin $\mathrm{S}$ and beta thalassemia in the south of Turkey. European Journal of Epidemiology. 1995;11(2):181-84. doi:10.1007/BF01719485.

16. Gür E, Yıldız I, Celkan T. Prevalence of anemia and the risk factors among school children in Istanbul. $J$ Trop Pediatr. 2005;51(6):346-50. doi:10.1093/tropej/fmio32.

17. Gazi Üniversitesi Tıp Fakültesi. Türkiye'de 6-17 Aylık Çocuklarda ve Annelerinde Hemoglobin Ferritin D -Vitamini Düzeyi ve Demir Eksikliği Anemisi Durum Belirleme Yürütülen Programların Değerlendirilmesi Araştırması. Sağlık Bakanlığı Yayınları No: 873, Ankara,2011. 
18. Stevens GA, Finucane MM, De-Regil LM, et al. Global, regional, and national trends in haemoglobin concentration and prevalence of total and severe anaemia in children and pregnant and non-pregnant women for 1995-2011: a systematic analysis of population-representative data. Lancet Glob Health. 2013;1:E16-E25. doi:10.1016/S2214- 109X(13)70001-9.

19. Kılıc A, Gokcay G. Cocuklarda demir eksikliği anemisine yaklaşım. Surekli Tıp Ĕ̆itimi Dergisi. 1999;8(11). URL: https://www.ttb.org.tr/STED/sted1199/st11992.html Erişim Tarihi: 22 Nisan 2020.

20. Canatan D, Köse MR, Üstündağ M, Haznedaroğlu M, Özbaş S. Hemoglobinopathy Control Program in Turkey. Community Genet. 2006;9(2):124-6. doi:10.1159/000o91493.

21. Turkish Society of Hematology (TSH)[Internet]. Beta thalassemia trait and disease www.thd.org.tr. Erişim tarihi 29 Ocak 2020.

22. Powers JM. Iron requirements and iron deficiency in adolescents. Uptodate http://www.uptodate.com. Yayınlanma tarihi Mart 2020. Erişim tarihi: 30 Nisan 2020.

23. “Bebek, Çocuk, Ergen İzlem Protokolleri,” T.C. Sağlık Bakanlığı Halk Sağlığı Genel Müdürlüğü, yayın no: 1112, Ankara, 2018.

24. Kılıçaslan Ö, Yıldırmak ZY, Urgancı N. Derin anemi nedeni ile çocuk kliniğine yatırılıp demir eksikliği tanısı alan olguların değerlendirilmesi. Şişli Etfal Hastanesi Tıp Bülteni. 2014;48(3):234-8. doi: 10.5350/SEMB.20140421022006.

25. Kaya Ü, Çetinkaya F, Yıldırmak Y, Kaya ÖA. Bir kent hastanesinin süt çocuğu servisinde izlenen ağır anemili hastaların değerlendirilmesi. ŞEH Tip Bülteni. 2003;37(4):36-9.

26. Ocak S, Kılıçaslan Ö, Yıldırmak ZY, Urgancı N. Adolesanlar ve anemi. Şişli Etfal Hastanesi Tip Bülteni. 2017;51(4):309-17. doi:

10.5350/SEMB.20170927094446. 